\title{
Nazopalatin Kanal Kisti: Üç Olgu Sunumu
}

\author{
Nasopalatine Duct Cyst: Three Case Reports
}

\author{
Günay YAPICI YAVUZ ${ }^{1}$ (D) \\ dtgunayyapici@hotmail.com
}

Şeyma BAYAZIT*1 ${ }^{* 1}$

uzmsymbyzt@gmail.com

\begin{abstract}
$\ddot{\mathbf{o z}}$
Nazopalatin kanal kisti en yaygın nonodontojenik kist olup, üst çene anterior bölgede lokalizedir. İnsiziv kanal kisti olarak da bilinir. Her yaş aralığında görülmekle beraber çoğunlukla orta yaş yetişkinlerde görülmektedir. Buna ek olarak erkeklerde kadınlara göre görülme oranı daha yüksektir. Nazopalatinal kanal kistinin etyolojisi tam olarak bilinmemekte olup, üst çenenin ön bölgesinde orta hatta kanal içerisindeki epitel artıklarından geliştiği düşünülmektedir. Genellikle asemptomatik olmakla birlikte travma, enfeksiyon ve idiopatik olarak farklı etken faktörlere bağlı çeşitli klinik semptomlar verebilir. Çoğunlukla rutin dental randevularda radyolojik muayene sonrası fark edilir. En sık şikayet orta hatta sert damağın önünde iyi sınırlı yuvarlak şişliktir. Radyolojik muayene sırasında ön tanı olarak teşhis edilmektedir. Kesin teşhis klinik, radyolojik bulgular ile birlikte histopatolojik inceleme ile konulmaktadır. Kistin tedavisinde cerrahi enükleasyon en çok tercih edilen tedavidir. Bazı büyük lezyonlu hastalarda ise marsüpzalizasyon kabul edilen alternatif bir tedavi şeklidir. Sunulan bu çalışmada klinik, radyolojik muayene ve histopatolojik inceleme sonucu nazopalatin kanal kisti tanısı konulan 3 vaka sunulmaktadır.
\end{abstract}

Anahtar Kelimeler: Nazopalatinal kanal kisti, Nonodontojenik kist, Enükleasyon

\begin{abstract}
Nasopalatine duct cyst is the most common nonodontogenic cyst, localized in the anterior upper jaw region. It is also known as incisive duct cyst. Although it is seen in all age groups, it is mostly seen in middle-aged adults. In addition, the incidence is higher in men than in women. The aetiology of the nasopalatine canal cyst is not certainly known, and it is thought to develop from epithelial residues in the midline canal in the anterior region of the upper jaw. Although it is generally asymptomatic, it can give various clinical symptoms due to different factors such as trauma, infection and idiopathic factors. It is mostly noticed after radiological examination in routine dental appointments. The most common complaint is a distinctly circumscribed round swelling in front of the midline hard palate. It is diagnosed as a preliminary diagnosis during the radiological examination. The definitive diagnosis is made by histopathological examination together with clinical and radiological findings. Surgical enucleation is the most preferred treatment in the treatment of the cyst. In some patients with large lesions, it is an alternative treatment that is accepted as marsupialization. In the present study, 3 cases diagnosed as nasopalatine duct cyst as a result of clinical, radiological examination and histopathological examination are presented.
\end{abstract}

Keywords: Nasopalatinal canal cyst, Nonodontogenic cyst, Enucleation

$\begin{array}{lll}\text { Received: } 16.03 .2021 & \text { Accepted: 28.05.2021 Published: 25.08.2021 }\end{array}$




\section{Gíriş}

Nazopalatin kanal kisti (NPKK), insiziv kanal kisti olarak da bilinir ve ilk kez 1914'de Meyer tarafından tanımlanmış olup, ağız boşluğunda en sık görülen nonodontojenik intraosseöz kisttir. ${ }^{1,2,3}$ Genel olarak nüfusun $\% 1$ ile $\% 2$ 'sinde görülmektedir. ${ }^{4}$ Erkeklerde kadınlara göre 3:1 oranında daha fazla görülür. ${ }^{3,5} \mathrm{Or}$ talama görülme yaşı $42.5^{\prime}$ tir. $^{2}$

NPKK'nın etiyolojisi tam olarak bilinmemektedir. NPKK, üst çenenin ön bölgesinde orta hatta nazopalatin kanal içerisinde nazopalatin kanal artıklarından gelișir. ${ }^{5}$ Travma, uyumsuz hareketli protezler, lokal enfeksiyon, genetik ve etnik köken, spontan proliferasyon, glandüler kanalların tıkanması nazopalatin kanal kistlerinin gelişimindeki etyolojik faktörler olarak sayılabilir. ${ }^{1,4,6}$

NPKK, asemptomatiktir ve genelde rutin dental radyolojik muayene sırasında fark edilir. En sık şikayet orta hatta sert damağın önünde iyi sınırlı yuvarlak șişliktir. ${ }^{7,8}$ Şişlik fluktuan ve mavi ise yüzeyeldir. Nazopalatin sinire baskı yaparsa yanma hissi veya palatal mukozada hissizlik oluşabilir. ${ }^{8}$ Altta yatan enfeksiyona bağlı olarak ağrı, drenaj, kaşıntı, fistül veya ülserasyon belirtileri görülebilir. ${ }^{1,9}$ NPKK'nin teșhisi için detaylı radyolojik inceleme gerekmektedir. $\mathrm{Bu}$ amaçla panoramik, periapikal, okluzal ve bilgisayarlı tomografi teknikleri kullanılabilir. Konvansiyonel radyografilerde maksilla interinsizal orta hatta iyi sınırlanmış oval, yuvarlak görünümün yanında anterior nasal spinanın superpozisyonuna göre kalp şeklinde radyolusent bir lezyon olarak da görülebilmektedir. ${ }^{2,8,10}$

Genellikle kist duvarı skuamöz hücre epiteli ile kaplıdır, ancak lezyon yukarı veya nazal bölgeye yakın yerleștiğinde solunum yolu epitel tipi görülebilir. ${ }^{6}$ Duvar aynı zamanda lifli doku, damarlar ve sinirler, küçük tükürük bezleri ve kıkırdak da içerebilir. ${ }^{1}$

NPKK'nin tedavisinde cerrahi enükleasyon en çok tercih edilen tedavidir. Büyük boyuttaki kistler ise marsüpyalizasyon ile tedavi edilebilmektedir. ${ }^{3}$

Bu çalışmada klinik ve radyolojik incelemelere dayanarak ön tanı nazopalatin kanal kisti olarak belirlenen ve sonrasında cerrahi olarak enükle edilen lezyonların histopatolojik incelemesinde nazopalatin kanal kisti tanısı konulan üç hastanın tedavi süreci vaka raporu olarak sunulmaktadır.

\section{OLGU SUNUMLARI}

\section{Olgu 1}

66 yaşında erkek hastaüst çene palatinal bölgesindeki enfeksiyon şikayeti ile kliniğimize başvurdu. İntraoral klinik muayenede hastanın bukkal sulkus bölgesinde ve palatinal bölgesi normal görünümde olup mukoza üzerinde ülserasyon, renk değişikliği, ödem, hiperplazi gibi herhangi bir patolojik bulguya rastlanmadı (Resim 1.). Alınan panoramik ve periapikal radyografilerde üst çenenin ön bölgesinde iyi sinırlı radyolüsent bir lezyon tespit edildi (Resim 2.). Detaylı inceleme amacıyla konik ışınlı bilgisayarlı tomografi (KIBT) çekildi. KIBT görüntülerinde palatinal bölgede kemik defekti mevcuttu (Resim 3.). Lezyon boyutu 21.0*26.0 mm'di. Komşuluğunda bulunan 12,11,21,22 nolu dişlerin vitalite değeri pozitif olup dişlerde mobilite yoktu. Hastanın tedavisinde lezyonun cerrahi olarak enükle edilmesine karar verildi.

Hastadan tedavi öncesi işlem hakkında bilgilendirilmiş imzalı onam alındı. Lokal anesteziyi takiben palatinal bölgeden sulkuler insizyon yapılarak flep kaldırıldı. Kistik lezyon kürete edildi ve kemik kenarları frez yardımı ile düzeltildi (Resim 4.). Palatinal flep 3/0 ipek sutur ile suture edildi. Postoperatif dönemde hastaya antibiyotik, analjezik ve gargara reçete edildi. Bir hafta sonra suturlar alındı ve postoperatif dönemde herhangi bir komplikasyon yaşanmadı. Yapılan patolojik inceleme sonucu lezyonun nazopalatin kanal kisti olduğu saptandı. Hasta 18 ay takip edildi ve alınan panoramik röntgende ilgili bölgenin tamamen kemikleștiği ve hastanın herhangi bir şikayetinin olmadığı görüldü.

Resim 1: Olgu 1'in ağız içi klinik görüntüsü

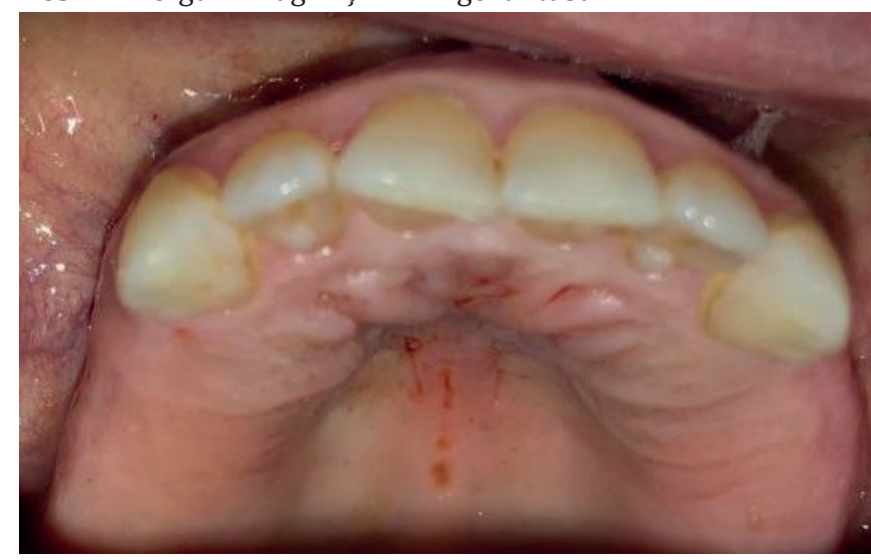

Resim 2: Olgu 1'in preoperatif periapikal radyografi görüntüsü

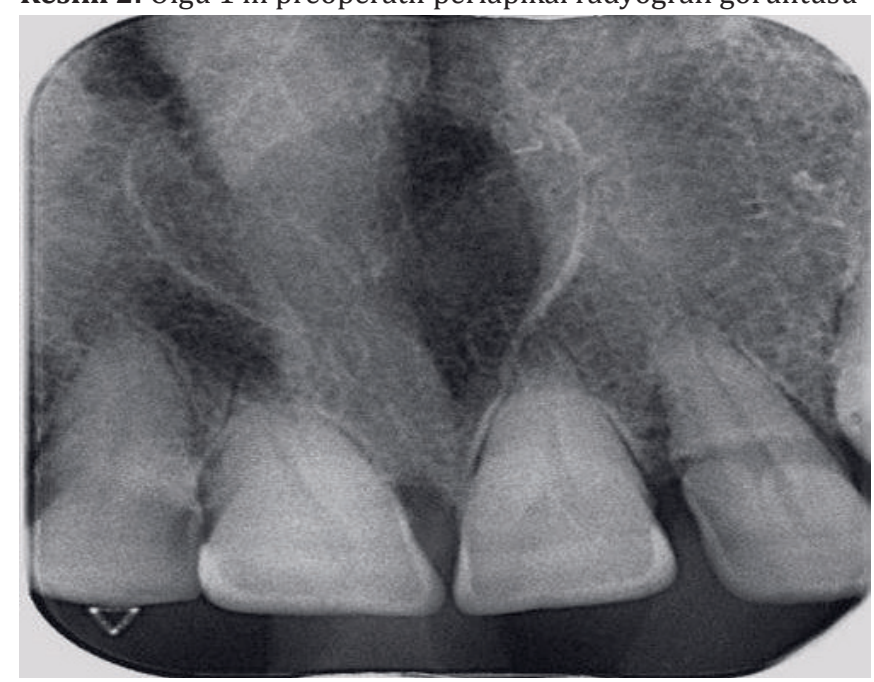


Resim 3: Olgu 1'in preoperatif koronal düzlem kesitinde KIBT görüntüsü

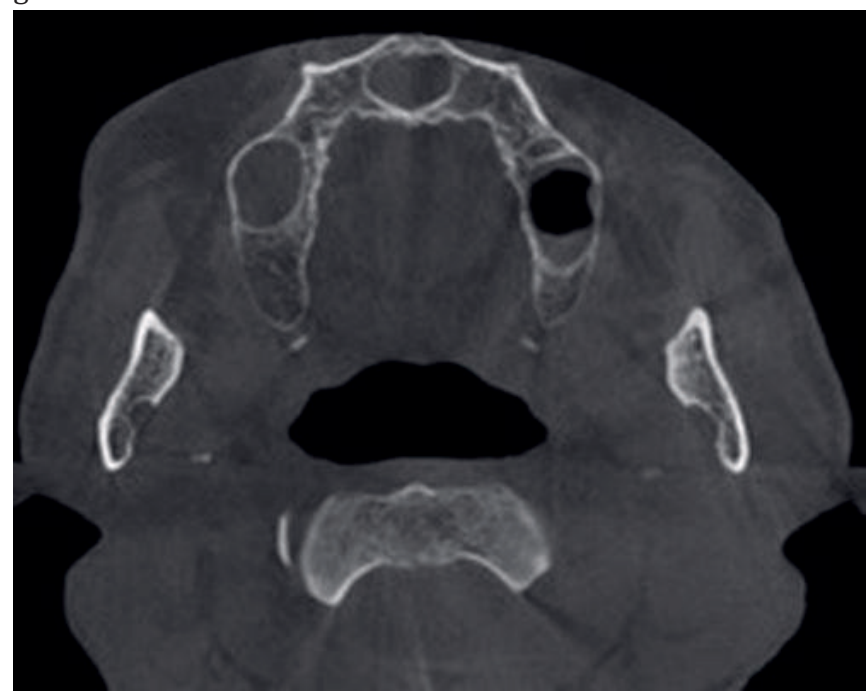

Resim 4: Olgu 1'in palatinalden kaldırılan flep ve NPKK'nin görüntüsü

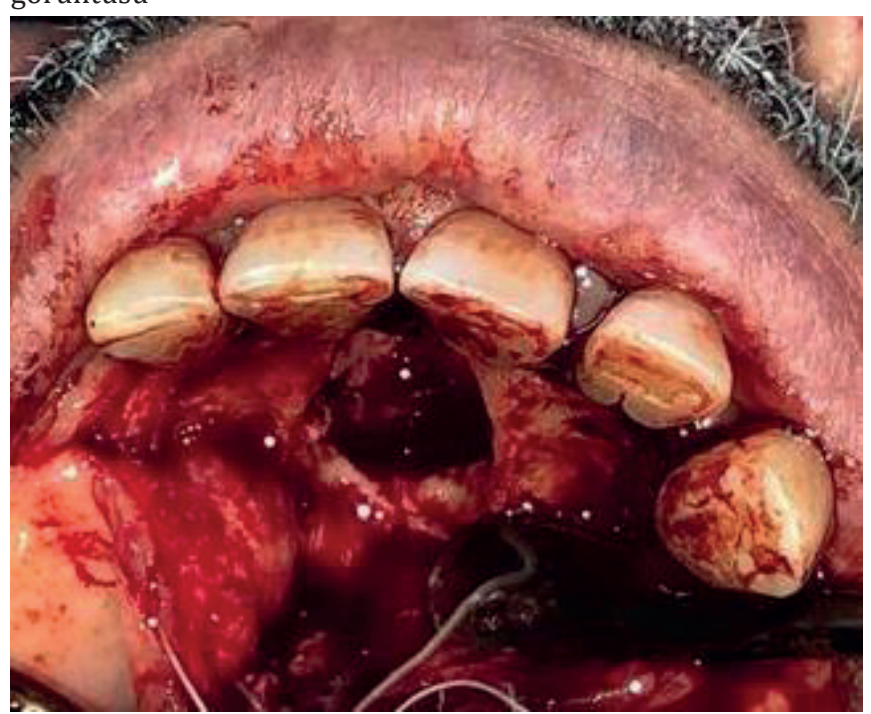

\section{Olgu 2}

60 yaşında kadın hasta ağzında kötü tat ve enfeksiyon şikayeti ile kliniğimize başvurdu. İntraoral klinik muayenede hastanın bukkal sulkus bölgesinde ve palatinal bölgede mukoza sağlıklı idi. Hastanın ağrı şikayeti yoktu (Resim 5.). Panoramik radyografide 11,21 nolu dişlerin apeksleri hizasında yuvarlak/oval radyolusent görüntü mevcuttu (Resim 6.). Hastanın KIBT görüntüsünde nazopalatinal kanal ile ilişkili kistik lezyon bulunmaktaydı. Lezyon boyutu 8.5*15.5 mm'di. Diş kökleri rezorbe değildi. Dişlerin vitalite değeri pozitif olup dişlerde mobilite yoktu.

Hastadan tedavi öncesi işlem hakkında bilgilendirilmiş imzalı onam alındı. Lokal anesteziyi takiben lezyon kürete edildi (Resim 7.). Yapılan histopatolojik inceleme sonucu lezyonun nazopalatin kanal kisti olduğu saptandı. Hasta 12 aylık takip sonucunda komplikasyon gelişmediği ve kist kavitesinin iyileştiği görüldü.
Resim 5: Olgu 2'nin ağız içi klinik görüntüsü

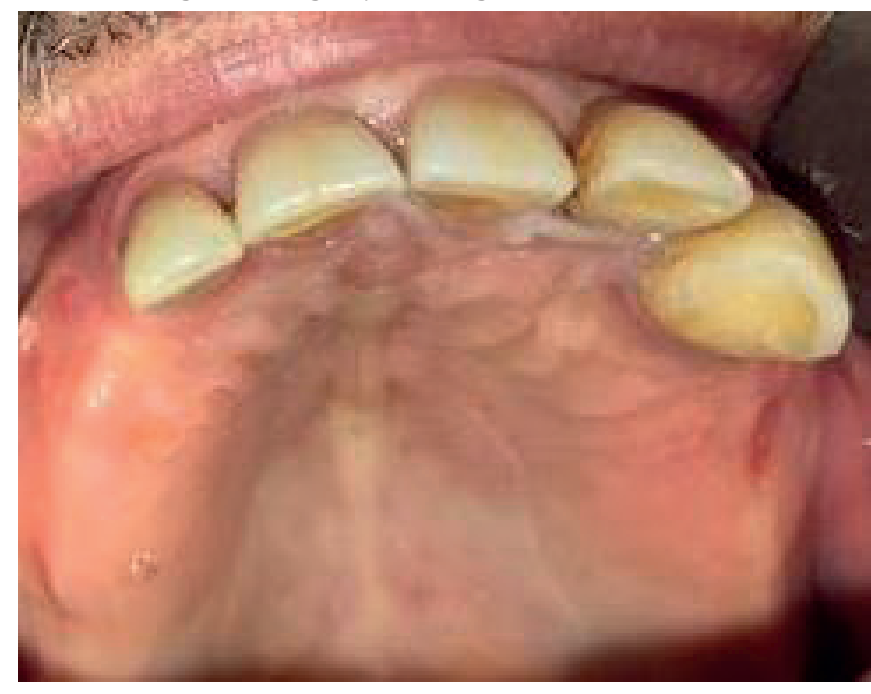

Resim 6: Olgu 2'nin preoperatif panoramik radyografi görüntüsü

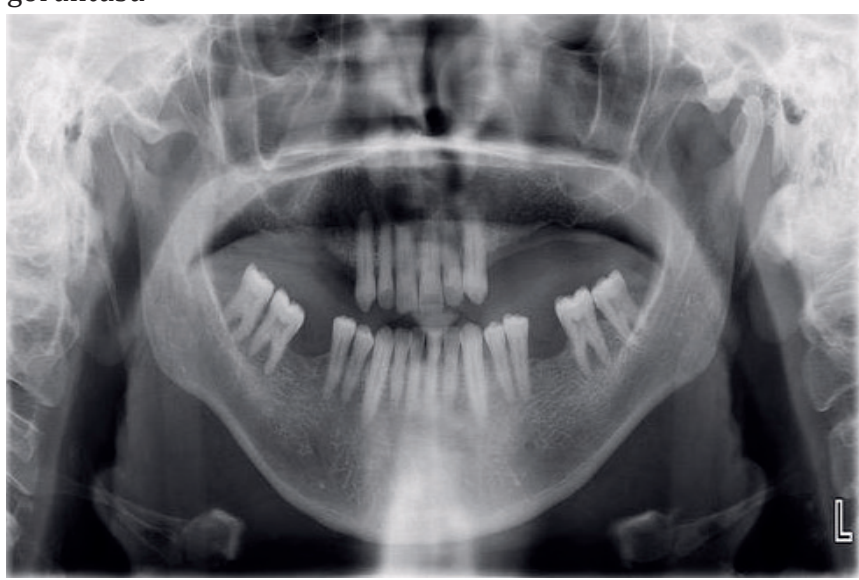

Resim 7: Olgu 2'nin palatinalden kaldırılan flep ve NPKK'nin görüntüsü

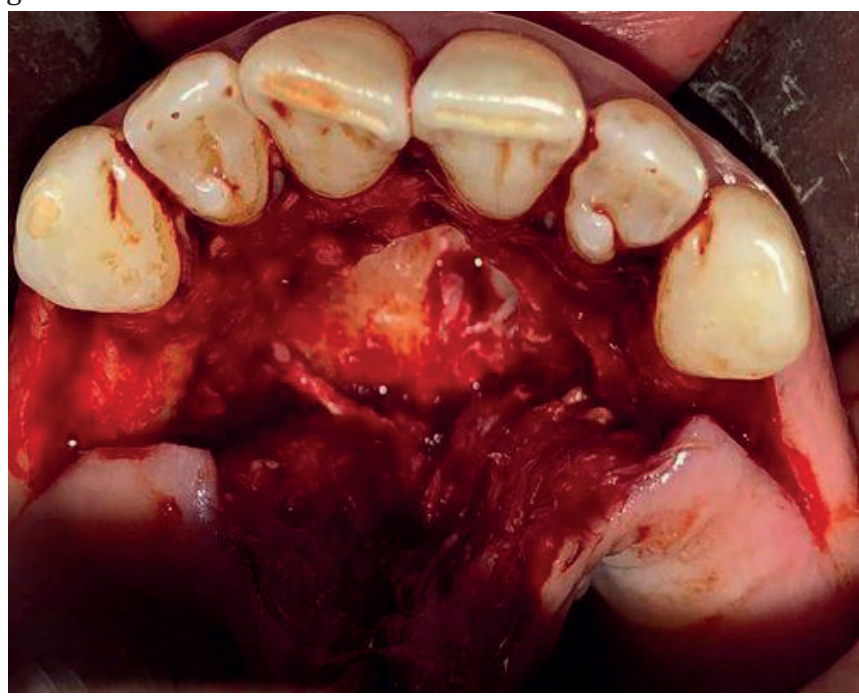




\section{Olgu 3}

70 yaşında erkek hasta protetik diş tedavisi öncesi radyografik görüntüsünde kistik lezyon fark edilmiş ve hasta kliniğimize yönlendirilmiştir. Hastadan alınan panoramik radyografide üst çene anterior bölgede yuvarlak sinırlı radyolusent görüntü mevcuttur (Resim 8.). İleri tetkik için KIBT alındı. Lezyon boyutu $18.0 * 15.0 \mathrm{~mm}$ 'di. Tam dișsiz olan hastanın ağrı şikayeti yoktu. İntraoral muayenede palatinal ve bukkal bölgede mukoza sağlıklı görünümde idi. Yapılacak olan total protez öncesi lezyonun büyüme ve enfekte etme ihtimaline karşı bölgedeki kistik lezyonun enükle edilmesine karar verildi. Hastanın yapılacak olan tedaviyi kabul ettiğine dair onam formu alındı. Lokal anesteziyi takiben lezyon kürete edildi. Yapılan histopatolojik inceleme sonucu lezyonun nazopalatin kanal kisti olduğu saptandı. Hasta 2 yıllık takip sonucunda komplikasyon gelişmediği ve kist kavitesinin iyileștiği görüldü (Resim 9.).

Resim 8: Olgu 3'ün preoperatif panoramik radyografi görüntüsü

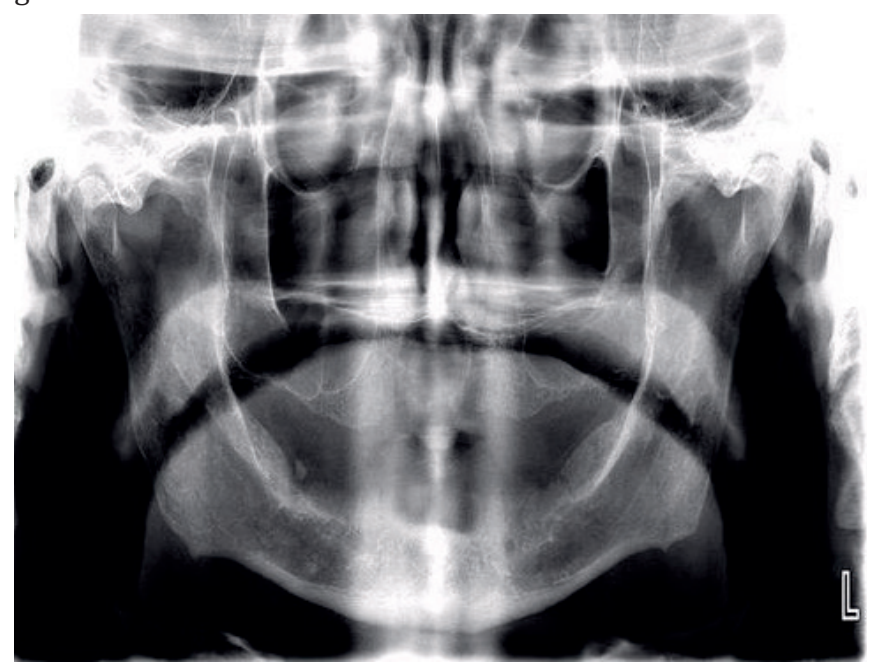

Resim 9: Olgu 3'ün postoperatif 2 yıl sonraki postoperatif panoramik radyografi görüntüsü

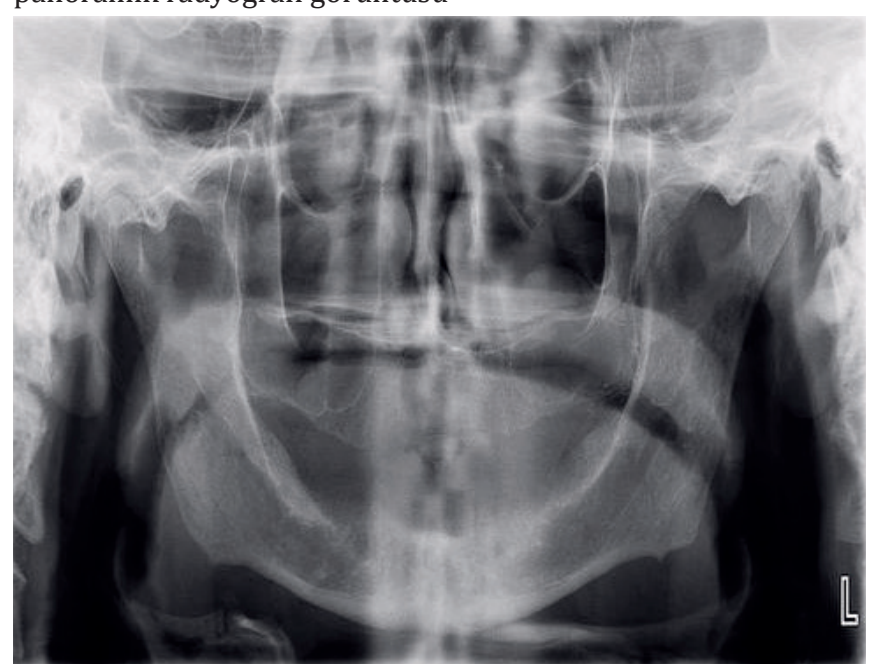

\section{TARTIŞMA}

NPKK, nazopalatin kanalın embriyonik epitel kalıntılarından türeyen ön damak orta hattında oluşan intraosseöz gelişimsel kistidir. ${ }^{9}$ Çoğunlukla 40-60 yaşlarda görülmekte olup çocuklarda nadir görülür. ${ }^{4}$ Sunulan çalışmada hastalar 60-70 yaş aralığındadır.

NPKK genellikle damakta asemptomatik șișlik olarak görülür. ${ }^{9}$ Enfekte olması durumunda sinüs oluşumu ve palatin papillada drenaj görülebilir. ${ }^{3}$ Escoda Froncoli ve arkadaşlarının ${ }^{10}$ çalışmasında 22 hastanın 14'ü asemptomatikti. ${ }^{10}$ Semptomlar bildirildiğinde, ağrı ve şişlik en sık görülen semptomlardandır, ayrıca hareketli protez takamama durumu, ağızda tat değişikliği, damakta uyuşma, kaşıntı ve yanma gözlenebilir.9,10,12 NPKK ile ilişkili enfeksiyon olan vakaların \%81'inde genellikle ağrı bulgusu görülmüştür. ${ }^{9}$ Büyük bir insisiv kanal kisti diş formunu ve düzenini bozabilir, sublabial bölgede şişliğe, çevre kemikte tahribata ve burun tabanının ekspanse olmasına neden olabilir. ${ }^{1,7}$ Sunduğumuz çalıșmada hastaların ikisinde enfeksiyon şikayeti bulunmakta olup, hastalardan biri ise asemptomatiktir.

Üst çenenin orta hattında veya yakınında yer alan lezyonlar radyografta genellikle 1-2 cm çapında iyi sinırlandırılmış radyolusent görüntü verir. Nadiren internal distrofik kalsifikasyonlar görülebilir. ${ }^{8}$ Kimberly ve arkadaşının ${ }^{9}$ yapmış olduğu çalışmada lezyonların boyutları 0.5 ile $5.2 \mathrm{~cm}$ arasında değișmektedir. ${ }^{9}$ Sunduğumuz çalışmada lezyon boyutlarının çapı 8.5 ile $27.0 \mathrm{~mm}$ arasındaydı. Röntgen görüntüsü ağırlıklı olarak yuvarlak veya ovaldir. ${ }^{10}$ NPKK orta hat veya yakınında tek bir radyolusent lezyon olabildiği gibi nadir de olsa bilateral insisiv kanal kisti șeklinde görülebilir. ${ }^{11}$ Sunduğumuz çalışmada kistler orta hatta tek bir odakta konumlanmıştı.

NPKK spesifik bir bölgede lokalize olmasına rağmen bazı lezyonlar ile karışabilmektedir. Bu nedenle ayırıcı tanıda: genişlemiş nazopalatin kanalı, median palatinal kisti, santral dev hücreli granülom, santral kesici dişin periapikal kisti, radiküler kist, lateral periodontal kist, odontojenik keratokist, ameloblastoma, odontojenik miksoma, kahverengi hiperparatiroid tümörü, santral hemanjiyom, supernümerer (mesiodens) diș foliküler kisti, primordial kist, nazoalveoler kist, palatal fistülizasyonlu osteit, bukkonazal veya bukkosinozal ilişki ve intraosseöz schwannom düşünülmelidir.,13,14,15 Nazopalatin kanal bölgesi, santral kesicilerin biri veya her ikisinin apekslerinin insiziv kanal ile radyografik olarak üst üste binmesinin yanlış endodontik tanıya ve yanlış tedaviye yol açabilir. Bir diğer ihtimal, bir nazopalatin kanal kisti enfekte olabilir ve endodontik kaynaklı bir lezyonu taklit edebilir. Uygun tanı testleri yapılarak ve bölgenin normal anatomisi hakkında bilgi sahibi olarak yanlış teşhis önlenebilir. ${ }^{16,18} \mathrm{Bu}$ nedenle 
ilgili dișlerin vitalite durumuna bakılmalı, erken dönemde kemik lezyonlarını tespit edebilen oral yapıların ayrıntılı üç boyutlu görüntülerini üreten KIBT görüntüleme tekniği uygulanmalıdır. Ancak görüntüleme teknikleri, lezyonun tanısında histopatolojik inceleme kriteri kadar doğru değildir. ${ }^{19}$ KIBT görüntüleme tekniği ile kistin sınırları daha hassas değerlendirilmektedir. Kiste komșu dișlerin lamina duraları sağlamdır, ancak lezyonlar maksiller kesici dişlerin köklerinin farklılaşmasına ve nadiren de olsa eksternal kök rezorpsiyonuna neden olabilir. ${ }^{3}$ Sunduğumuz çalışmada hastaların ilgili dişlerinde lamina duraları normal olup, kök rezorpsiyonu yoktu.

NPKK'nın tedavisinde cerrahi enükleasyon, düşük nüks oranı nedeniyle en çok tercih edilen tedavi seçeneğidir. ${ }^{11}$ Asemptomatik küçük boyuttaki kistler için cerrahi tedavi gerekmeyebilir. ${ }^{20}$ Büyük boyuttaki kistlerde enükleasyondan önce marsüpzalizasyon tedavisi de yapılabilmektedir. ${ }^{3}$ Genel olarak \% 30'a kadar bir nüks etme oranı bildirilmiștir. ${ }^{10,20}$ Swanson ve arkadaşlarının ${ }^{12}$ çalışmasında \%2 nüks oranı görülmüştür. ${ }^{12}$ Maligniteye dönüşüm son derece nadir olmakla birlikte, nazopalatin kanal kistinden geliştiği düşünülen skuamöz hücreli karsinom gelişimi vakası bildirilmiştir. ${ }^{21}$ Sunulan çalışmada takipler sonucunda nüks görülmedi.

\section{SONUÇ}

Literatür bilgilerine göre NPKK genellikle asemptomatiktir ve rutin diş muayenelerinde daha dikkatli radyografik inceleme yapılmall, yanlış teşhisten kaçınmak için klinik bulgular ile radyografik bulgular eşleştirilmelidir.

\section{KAYNAKLAR}

1. Lake S, Iwanaga J, Kikuta S, Oskouian RJ, Loukas M, Tubbs RS. The incisive canal: A comprehensive review. Cureus. 2018;10:1-11.

2. Bereket C, Kaynar M. Nasopalatine duct cyst concurrent with supernumerary tooth: A case report. J Dent Fac Atatürk Univ. 2015;23:98-102.

3. Philbert RF, Sandhu NS. Nonodontogenic Cysts. Dent Clin North Am. 2020;64:63-85.

4. Scolozzi P, Martinez A, Richter M, Lombardi T. A nasopalatine duct cyst in a 7-year-old child. Pediatr Dent. 2008;30:530-4.

5. Ezirganlı S, Köşger H, Kırtay M. Nazopalatin kanal kisti: Bir olgu sunumu nasopalatıne. GÜ Diş Hek Derg. 2010;27:195-9.
6. Cecchetti F, Ottria L, Bartuli F, Bramanti NE, Arcuri C. Prevalence, distribution, and differential diagnosis of nasopalatine duct cysts. Oral Implantol (Rome). 2012;5:47-53.

7. Ueda N, Tanaka T, Oda M, et al. Advocacy of diagnostic criteria for maxillary incisive canal cysts based on alteration of normal maxillary incisive canals according to aging in Japanese populations. Head Face Med. 2019;15:2-6.

8. Sindel A, Kaymak T, Yeğin E, Yeğin Z. Foreign body granuloma masquerading a nasopalatine duct cyst: Case report. J Dent Fac Atatürk Univ. 2015;42:185-8.

9. Elliott KA, Franzese CB, Pitman KT. Diagnosis and surgical management of nasopalatine duct cysts. Laryngoscope. 2004;114:1336-40.

10. Francolí JE, Marqués NA, Aytés LB, Escoda CG. Nasopalatine duct cyst: Report of 22 cases and review of the literature. Med Oral Patol Oral Cir Bucal. 2008;13:438-43.

11. Cicciù $M$, Battista Grossi G, Borgonovo $A$, Santoro G, Pallotti F, Maiorana C. Rare bilateral nasopalatine duct cysts: A case report. Open Dent J. 2010;4:8-12.

12. Swanson KS, Kaugars GE, Gunsolley JC. Nasopalatine duct cyst: An analysis of 334 cases. J Oral Maxillofac Surg. 1991;49:268-71.

13. Allmendinger A, Gabe M, Destian S. Median palatine cyst. J Radiol Case Rep. 2009;3:7-10.

14. Srivastava S, Misra N, Agarwal R, Pandey P. Nasopalatine canal cyst: Often missed. BMJ Case Rep. 2013;1:2-4.

15. Shylaja S, Balaji K, Krishna A. Nasopalatine duct cyst: Report of a case with review of literature. Indian J Otolaryngol Head Neck Surg. 2013;65:385-8.

16. Gnanasekhar JD, Walvekar SV, Al-Kandari AM, Al-Duwairi Y. Misdiagnosis and mismanagement of a nasoplatine duct cyst and its corrective therapy. A case report. Oral Surgery, Oral Med Oral Pathol Oral Radiol. 1995;80:465-70.

17. Hilfer PB, Bergeron BE, Ozgul ES, Wong DK. Misdiagnosis of a nasopalatine duct cyst: A case report. J Endod. 2013;39:1185-8.

18. Dwight Moss H, Hellstein JW, Johnson JD. Endodontic considerations of the nasopalatine duct region. J Endod. 2000;26:107-10.

19. Faitaroni LA, Bueno MR, Carvalhosa AA, Mendona EF, Estrela C. Differential diagnosis of apical periodontitis and nasopalatine duct cyst. J Endod. 2011;37:403-10.

20. Pavankumar K, Sholapurkar AA, Joshi V. Surgical Management of Nasopalatıne duct Cyst : case report Título Tratamento cirúrgico do cisto nasopalatino : relato de caso. Rev Clín Pesq Odontol. 2010;6:81-6.

21. Takagi R, Ohashi Y, Suzuki M. Squamous cell carcinoma in the maxilla probably originating from a nasopalatine duct cyst: Report of case. J Oral Maxillofac Surg. 1996;54:112-5. 